\title{
nature
}

\section{Taking lessons from the new philanthropists}

Philanthropies are invigorating US biomedical science by liberating talented researchers from the bureaucracy that surrounds traditional peer review. The NIH should consider distributing a small proportion of its funds in a similar way.

$\mathrm{T}$ he truism that diversity is strength is borne out by the current health of the biomedical research enterprise in the United States. The past few years have seen a surge in philanthropic funding for biomedicine. Entrepreneurs who made their fortunes in high-tech industry have started giving their spare millions to leading researchers (see page 140), and established players such as the Howard Hughes Medical Institute (HHMI) have continued to grow.

With the budget of the National Institutes of Health (NIH) also on the rise (see page 134), there is much for bench researchers to celebrate. But the new philanthropists have done more than simply increase the resources available for biomedical research. They have also provided an alternative to the bureaucracy associated with traditional grant applications. Rather than asking researchers to fill in forms running to 25 pages or more, and subjecting these to careful, but cumbersome, peer review, some philanthropists have adopted an aggressive strategy of picking potential winners. For the researchers singled out, the experience is liberating. The treadmill of chasing federal research dollars is replaced by a refreshing focus on producing results.

It would be foolish to suggest that the NIH should abandon its traditional 'study sections', through which peer-review panels consider the merits of competing proposals. This system may be conservative and slow, but it is the most accountable way of ensuring quality control that we know. In a period of long-term budget growth, however, the NIH should consider whether some of its riches might be distributed using similar methods to those adopted by the new philanthropies.

There is otherwise a danger that the NIH will find itself becoming the second port of call for the most talented biomedical researchers. The HHMI supports only around 350 investigators, but these individuals account for a disproportionate number of the most highly cited papers. And if one of Silicon Valley's multimillionaires is prepared to give you hundreds of thousands of dollars to pursue a novel line of research, why bother waiting around for NIH funding?

There is also the long-term health of US biomedicine to consider. The NIH could argue that established foundations and the new philanthropies are already ensuring a diversity of modes of funding. But philanthropists can take away, as well as give. High-tech companies are already feeling the chill winds of an economic slowdown. And as their founders begin to feel the pinch, there can be no guarantee that they will continue pouring money into biomedical research labs.

In rising to this challenge, the NIH does not even have to invent a model of federal research funding. It could simply follow the example of the Defense Advanced Research Projects Agency (DARPA). This body hires temporary programme managers from academia, and gives them almost complete freedom to fund innovative, high-risk projects. Despite its lack of obvious accountability, Congress tolerates this model because DARPA contributes to national security. Do the potential gains for human health not justify spending a few hundred million dollars of the NIH's budget in a similar way?

\section{A portal for physics}

\section{Nature is introducing a new online gateway into a flourishing and diverting discipline.}

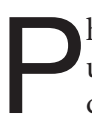
hysicists may not have been smiled on by the advisers who drew up US President George W. Bush's first budget request, but their discipline is going through exciting times, nevertheless.

Last week, for example, Nature published the report of the discovery of a surprising new superconductor, magnesium diboride (see Nature 410, 63-64; 2001). This is thought to work by a conventional mechanism, but has an unprecedentedly high transition temperature for this type of superconductor, and seems not to suffer from the limitations that have afflicted the high- $T_{\mathrm{c}}$ copper oxide materials (see page 186). Next week's meeting of the American Physical Society in Seattle is already attracting a buzz of excitement not dissimilar to the tumult that followed the discovery of the copper oxides. Thanks to the unpredictable character of condensed matter, the rule in this area of physics seems to be that delightful surprises can be confidently expected - leaving new technologies flowing in their wake.

Other areas of physics are also flourishing. Device physics is feeding the revolution in communications and computing, with spintronics, single-electron devices and photonics all making rapid headway. Computational physics is helping to bridge the gap between micro- and macroscopic behaviours of simple and complex systems. At the fundamental level, Bose-Einstein condensates are opening up new territory for exploring quantum mechanics. And that is just to focus on 'small' physics - the big-science disciplines of high-energy physics and astrophysics are similarly thriving.

Nature has enjoyed its own resurgence in physics content in recent years, following a dearth dating back to the Second World War. Now we are going a step further. On 12 March we launch the Nature Physics Portal (http://physics.nature.com), intended to ease access not only to original research published in Nature, but also to that appearing elsewhere.

There are other features too - including some high-level fun. We hope the 'problem page', which offers real-world problems for physicists (and anyone else interested) to solve, will prove an amusing diversion. The principle here is one imbued in the training of all physicists: that they should be able to answer almost any question on the way the world works, armed with a few basic principles, the skill to combine them with order-of-magnitude numbers, and the ability to think. Maybe this is what makes physicists so valuable to the society that supports them. Perhaps Bush's advisers should take note. 